\title{
Surface Ictal Electroencephalographic Patterns in Frontal vs Temporal Lobe Epilepsy
}

\author{
Barbara E. Swartz, Gregory O. Walsh, Antonio V. Delgado-Escueta and Paolo Zolo
}

\begin{abstract}
The effectiveness of long term EEG monitoring in the localization of the epileptic focus was studied in 37 patients with temporal lobe epilepsy comprising 190 recorded seizures, in 19 frontal lobe epileptic patients with 172 recorded seizures and in 12 additional patients which were classified as fronto-temporal. In the temporal lobe group, $49 / 190$ seizures began focally (26\%) and $20 / 190$ seizures exhibited a regional onset (10\%). In the frontal lobe group, only 21 out of 172 seizures ( $12 \%$ ) had a focal ictal onset. $41 / 172$ seizures began regionally (24\%). In the fronto-temporal group, $31 / 55$ seizures disclosed a focal EEG onset $(57 \%)$. This study demonstrates that there is a two-fold increase in seizures beginning focally in the temporal lobe epilepsy group versus the frontal lobe group.
\end{abstract}

RÉSUMÉ: Caractéristiques à l'électroencéphalographie ictale de surface de l'épilepsie frontale vs temporale. L'efficacité du monitoring EEG prolongé dans la localisation des foyers épileptiques a été évaluée chez 37 patients avec épilepsie temporale (190 crises ont été enregistrées), 19 avec épilepsie frontale (172 crises enregistrées) et 12 avec crises classifiées fronto-temporales. Dans le groupe des épileptiques temporaux, $49 / 190$ crises (26\%) avaient un point de départ EEG focal et 20/190 avaient un début régional (10\%). Dans le groupe des épilepsies frontales, seulement 21 des 172 crises enregistrées (12\%) avaient un début focal, alors que 41 des 172 crises (24\%) avaient un point de départ régional. Dans le groupe des patients fronto-temporaux, 31 des 55 crises (57\%) ont été à début focal. Cette étude démontre que la proportion des crises à départ focal est deux fois supérieure chez les patients avec épilepsie temporale par rapport à ceuz qui souffrent d'épilepsie frontale.

Can. J. Neurol. Sci. 1991; 18: 649-662

This topic is hardly new to epileptologists who for years have attempted to predict the underlying brain pathophysiology from a remote current source based on the surface EEG. The practical and theoretical disadvantages of this approach have been all reviewed by other authors 1.3 and will not be discussed here. Rather some of the literature on surface EEG, primarily ictal, in frontal and temporal lobe epilepsy will be presented to point out differences of opinion and areas of controversy. Our data will be presented and then discussed with respect to previous studies and planning for surgical resection.

Nearly 30 years ago, Fegersten and Roger wrote, "In spite of the fact that human frontal lobes are being injured daily in motor car accidents, frontal lobe lesions producing epilepsy have received little attention." 4 This situation has been improved upon by well known publications such as those of Rasmussen 5.6 Ajmone-Marsan and collaborators, 7,8,10 Williamson et al.,"11-13 Quesney and collaborators, 3,14,15 Bancaud and collaborators, 16-19 the Cleveland Clinic group $20,20 \mathrm{a}$ and by the Comprehensive Epilepsy Program of California. ${ }^{21-23}$ Nevertheless, the basic understanding of the diagnosis, pathophysiology and management of this type of focal epilepsy does not approach the experience with temporal lobe epilepsy which is either more frequent or more intractable or both. Frontal lobe epilepsy appears to account for $15 \%^{24}$ to $30 \%{ }^{13}$ of focal epilepsies. The remainder are generally ascribed to temporal lobe epilepsy although in one small series parietal seizures were equal in frequency to frontal seizures. ${ }^{25}$ Recently, Delgado-Escueta ${ }^{26}$ has published an algorithm for distinguishing temporal from frontal lobe complex partial seizures. The algorithim does not specify particular EEG characteristics common to one or the other. This issue will therefore be addressed in this chapter.

The interictal EEG is frequently of value in localizing the epileptic focus. 1,5,27-33a However, the ability to record from inferior, mesial or mesial-basal structures is limited. ${ }^{1-3}$ Some studies by the same authors above and others specifically question the use of the surface interictal EEG. ${ }^{2,33-37}$ Intracranial recordings naturally improve the localizability of the epileptogenic zone. $2,8,10,38-42$ The ictal EEG is felt to be the best non-invasive

From the Neurology and Research Services, VA Southwest Regional Epilepsy Center, VAMC W. Los Angeles, Wadsworth Division, and the Comprehensive Epilepsy Program, Los Angeles (B.E.S., A.V.D-E.); the Department of Neurology, UCLA School of Medicine, Los Angeles (B.E.S., G.O.W., A.V.D.-E); the Comprehensive Epilepsy Program, Santa Monica Medical Center, Santa Monica, Epilepsy Center, Arezzo Hospital, Arezzo, Italy (P.Z.)

Reprint requests to: Barbara E. Swartz, M.D., Ph.D., Epilepsy Svc (W127B), VAMC Wadsworth, Los Angeles, Califomia, U.S.A. 90073 
indicator of the epileptogenic zone but false localizations have been reported on surface $E E G^{31.43}$ and on depth ictal recordings $\mathrm{s}^{44}$ in the presence of large gliotic or tumorous lesions. Nevertheless, it is possible to record very focal interictal abnormalities in patients with diffuse intracranial ${ }^{10}$ or extracranial onsets. ${ }^{45}$ (Also see Figures 3-5 this paper).

Quesney, having reviewed these problems in detail $3,14,15$ concluded that the large disparities between different groups' reports of interictal and ictal EEG discordance (5-33\%) were likely due largely to differences in the methodology of interpretation of the EEG's. One study confirmed this by reporting extremely low interobserver agreement for all foci with respect to surface and even depth ictal EEG data. ${ }^{43}$

The above cited literature is dominated by reports on temporal lobe epilepsy. When one comes to the problem of distinguishing frontal from temporal lobe seizures there are no clearly defined EEG criteria. It is well known that rapid spread of ictal discharges occurs from temporal to frontal lobes or vice versa throughout the uncinate fasciculus or cingulum ${ }^{45,46}$ making interpretation difficult. Frontal lobe foci may appear indistinguishable from primary generalized epilepsy with bilaterally synchronous spike and wave patterns. $16,46-51$ To further complicate matters, Gastaut has noted that medial frontal lobe foci may appear with temporal EEG maxima, ${ }^{52}$ which we have also noted.

Tables $1 \mathrm{~A}$ and $1 \mathrm{~B}$ were constructed from previous publications to show the range of data on localizability of surface EEG in temporal and frontal lobe epilepsy. They are not intended to be comprehensive. In temporal lobe epilepsy the interictal EEG was found to be focal or localizing in $30-55 \%$ of records, while ictal onsets were focal or localizing in $41-94 \%$ of records. In frontal lobe epilepsy the interictal EEG was focal or localizing in 13 to $72 \%$ with $4-100 \%$ of ictal records providing localizing information, showing the greater disagreement among investigators with regard to frontal than temporal lobe epilepsy.

\section{Methods}

Patients referred for evaluation of intractable seizures were classified according to: 1) their electroclinical manifestations as observed with CCTV-EEG ictal recordings, 2) corroborative neuroimaging (CT, MR, and FDG-PET scans), and 3) neuropsychological investigations, as temporal, frontal, frontal-temporal (or temporal-frontal) or frontal-parietal. Thirty-seven patients with temporal lobe seizures as verified by results of intracranial monitoring and/or surgical excision were studied. In this group, 190 seizures and 43 interictal EEG's were available for review. Nineteen patients were classified as having frontal lobe epilepsy. Twelve of these have undergone surgery while in 7 the localization is presumed on the basis of the presurgical evaluation as mentioned above. In these 19 frontal lobe patients, 172 seizures and 27 interictal EEG's have been reviewed. Twelve other patients fell into a temporal-frontal $(n=8)$ or frontal-temporal classification $(n=4)$. Seven of these have had intracranial

Table 1A: Localizing Value of Interictal and Ictal EEG in Focal Seizure Disorders (Temporal)

\begin{tabular}{|c|c|c|c|c|}
\hline Author & $\begin{array}{c}\text { Accuracy of } \\
\text { Interictal EEG }\end{array}$ & $\begin{array}{l}\text { Accuracy of } \\
\text { Ictal EEG }\end{array}$ & Lobe & $\begin{array}{l}\text { No. of } \\
\text { Patients }\end{array}$ \\
\hline Christodoulou, 1967 & $52 \%$ focal sphenoid spike & Not available & Presumed temporal & 102 \\
\hline Theodore et al., 1983 & $\begin{array}{l}40 \% \text { focal or mainly focal } \\
50 \% \text { multifocal or bilateral } \\
7 \% \text { diffuse slow } \\
8 \% \text { normal }\end{array}$ & $50 \%$ focal & Temporal & 40 \\
\hline Spencer, et al., 1983 & $\begin{array}{l}50 \% \text { localized } \\
14 \% \text { lateralized } \\
14 \% \text { bilateral } \\
16 \% \text { falsely localized } \\
\text { or noninformative }\end{array}$ & Not available & Mainly temporal & $\begin{array}{l}27 \text { patients } \\
\text { and EEGs }\end{array}$ \\
\hline Spencer, et al., 1985 & Not available & 51-61\% localizable & Temporal & 27 \\
\hline $\begin{array}{l}\text { Estimated by B.E. Swartz from } \\
\text { Quesney et al., } 1984 \text { and } \\
\text { Quesney \& Gloor } 1987\end{array}$ & Not available & $\begin{array}{l}47 \% \text { focal or regional } \\
31 \% \text { bilateral } \\
22 \% \text { uninformative }\end{array}$ & Temporal & 148 \\
\hline $\begin{array}{l}\text { King et al., } 1986 \\
\text { Dodrill et al., } 1986\end{array}$ & $\begin{array}{l}\text { Not available } \\
31 \text { single focus } \\
39 \text { mainly temporal } \\
54 \text { anterior to mid-temporal } \\
35 \text { lateralized } \\
42 \text { noninformative }\end{array}$ & $\begin{array}{l}41 \% \text { localized at sphenoid } \\
\text { Not available }\end{array}$ & $\begin{array}{l}\text { Temporal } \\
\text { Mainly temporal }\end{array}$ & $\begin{array}{l}12 \\
75\end{array}$ \\
\hline Wyllie et al., 1987 & $60 \%$ focal & $94 \%$ focal & Temporal & 50 \\
\hline Risinger et al., 1988 & Not available & $\begin{array}{l}52 \% \text { focal sphenoidal } \\
24 \% \text { lateralized or } \\
\text { nonsphenoid localized } \\
24 \% \text { other patterns }\end{array}$ & Temporal & $\begin{array}{l}110 \text { patients } \\
706 \text { seizures }\end{array}$ \\
\hline
\end{tabular}


recordings and /or surgery to establish the localization while 5 are presumptive. These two groups were combined for reasons discussed later. In this group, 75 seizures and 17 interictal EEG's were available for review. 21 seizures and 5 interictal EEG's were reviewed from the group of 5 patients with frontalparietal foci.

All surface EEG's were recorded using 18-25 channels of silver/silver chloride or gold disk electrodes applied with colloidan according to the International 10-20 placement system. The interictal EEG's were 1 hour in duration, awake and asleep and usually included nasopharyngeal recordings. All ictal recordings had sphenoidal recordings. Additional electrodes, such as orbito-frontal, or placements in between the standard ones were used as deemed necessary. All EEG's were reviewed initially by a single board-certified electroencephalographer and later reviewed by three certified electroencephalographers in collaboration. Since the three reviewers have worked closely together for some years it was believed that attempts to co-verify each others readings with a blind design would necessarily be biased, so this was not done. Nearly all EEG's were independently reviewed by the principle author after the original interpretation was performed and any questions on interpretation were discussed amongst the three.

The EEG ictal onsets were defined as the following:

Table 1B: Localizing Value of Interictal and Ictal EEG in Focal Seizure Disorders (Frontal)

\begin{tabular}{|c|c|c|c|c|}
\hline Author & $\begin{array}{l}\text { Accuracy of } \\
\text { Interictal EEG }\end{array}$ & $\begin{array}{l}\text { Accuracy of } \\
\text { Ictal EEG }\end{array}$ & Lobe & $\begin{array}{l}\text { No. of } \\
\text { Patients }\end{array}$ \\
\hline Ludwig et al., 1975 & $\begin{array}{l}30 \% \text { focal ( } 14 \% \text { also had } \\
\text { secondary bilateral synchrony) } \\
35 \% \text { regional } \\
15 \% \text { bilateral or lateral } \\
15 \% \text { no spikes }\end{array}$ & Not available & Frontal Lobe & $\begin{array}{c}14 \text { cases } \\
\text { (total } 28 \text { extra } \\
\text { temporal patients) }\end{array}$ \\
\hline Quesney et al., 1984 & $\begin{array}{l}22.5 \% \text { focal } \\
40 \% \text { regional } \\
18 \% \text { lateral } \\
4.5 \% \text { bilateral } \\
9 \% \text { normal }\end{array}$ & $\begin{array}{l}22 \% \text { focal or regional* } \\
11 \% \text { lateral } \\
37 \% \text { bilateral } \\
30 \% \text { noninformative } \\
\text { *30\% focal with } \\
\text { supraorbital or } \\
\text { nasopharyngeal electrodes }\end{array}$ & Frontal Lobe & $\begin{array}{l}22 \text { patients } \\
302 \text { seizures }\end{array}$ \\
\hline Williamson et al., 1985 & $\begin{array}{l}50 \% \text { misleading } \\
20 \% \text { secondary bilateral } \\
\text { synchrony } \\
30 \% \text { unavailable }\end{array}$ & $\begin{array}{l}70 \% \text { obscured by artifact } \\
30 \% \text { (?) post-ictal } \\
\text { generalized slowing }\end{array}$ & Frontal Lobe & 10 \\
\hline Spencer et al., 1985 & Not available & $12-21 \%$ localizable & Frontal Lobe & 7 \\
\hline Wyllie et al., 1987 & $\begin{array}{l}40 \% \text { focal frontal } \\
30 \% \text { focal fronto-parietal }\end{array}$ & $100 \%$ localizable & Frontal Lobe & 10 \\
\hline Quesney, 1987 & $\begin{array}{l}13.5 \% \text { focal } \\
73 \% \text { frontal central } \\
13.5 \% \text { unreliable }\end{array}$ & Not available? & Frontal Lobe & $?$ \\
\hline Quesney \& Gloor, 1988 & Not available & $\begin{array}{l}22 \% \text { focal or regional } \\
11 \% \text { lateral } \\
37 \% \text { bilateral } \\
19 \% \text { uninterpretable } \\
11 \% \text { no change }\end{array}$ & Frontal Lobe & $\begin{array}{l}16 \text { patients } \\
302 \text { seizures }\end{array}$ \\
\hline Morris et al., 1988 & $\begin{array}{l}55 \% \text { focal } \\
36 \% \text { normal } \\
9 \%>\text { focus }\end{array}$ & $\begin{array}{l}19 \% \text { focal } \\
19 \% \text { lateralized } \\
27 \% \text { generalized } \\
27 \% \text { obscured } \\
6 \% \text { normal }\end{array}$ & Frontal Lobe & 17 \\
\hline Fegersten and Roger, 1961 & $\begin{array}{l}33 \% \text { focal } \\
33 \% \text { regional } \\
30 \% \text { regional plus bilateral } \\
13.5 \% \text { focal } \\
73 \% \text { frontal central } \\
13.5 \% \text { unreliable }\end{array}$ & Not available? & Frontal Lobe & $\begin{array}{l}30 \text { patients } \\
\text { and EEGs } \\
10 \text { seizures }\end{array}$ \\
\hline Veilleux et al., 1990 & $\begin{array}{l}46 \% \text { lateralized } \\
4 \% \text { localized }\end{array}$ & $96 \%$ diffuse onset & Frontal Lobe & 23 \\
\hline
\end{tabular}


1. Focal - rhythmical spikes or sharp waves with phase reversals seen clearly at one electrode on bipolar recordings (Figure 1), or focal attenuation (Figure 2). The field could extend from one to three contiguous electrodes including sphenoidal. A fourth electrode could be included if it was between standard placements. An example of a focal ictal onset is seen in Figure 1.

2. Regional - rhythmical spikes, sharp or slow waves or attenuation arising within one lobe. A regional ictal onset is noted in Figure 3.

3. Lateral - rhythmical spike and wave or sharp waves or polyspikes, slowing, or attenuation confined to one side.

4. Bilateral - rhythmical sharp waves, spike and wave, polyspikes, or attenuation (low voltage fast activity) seen across both hemispheres.

In a previous publication, if a pattern which developed into a phase reversing spike or sharp wave at a sphenoid electrode occurred within 30 seconds, it was arbitrarily considered to be focal, 53 while others have stated that the sphenoidal pattern should appear at the beginning or within "a few seconds" of the clinical onset. 54 A previous study from our group of depth vs. sphenoidal patterns showed that frontal lobe seizures could present as a delayed sphenoidal focus. 55 This appears particularly problematic from cingular foci. 52 Our working definition of "onset" was the first to third seconds of electrographic change.

Similarly the interictal EEG's were classified as:

1. Focal - spikes or sharp waves at one to three contiguous electrodes with phase reversals at a single electrode, or focal polymorphic slow waves (Figures $4 a, 5 b$ ).

2. Regional - spikes, sharp waves, polymorphic delta, rhythmic slowing seen in one lobe. Multifocal spikes within one lobe could be included.

3. Lateral - rhythmical or polymorphic slowing or multifocal spikes or sharp waves confined to one hemisphere.

4. Bilateral - general background slowing, bifrontal rhythmical delta, bilaterally synchronous spike and wave (Figures $4 \mathrm{~b}$, $5 a)$ or sharp waves or multifocal bilateral sharp waves or spikes.

\section{Results}

\section{Temporal Lobe Epilepsy}

Of the 190 recorded seizures, 49 began focally (26\%), 20 (10\%) began as a regional pattern, 2 began laterally, $70(47 \%)$ began with diffuse attenuation while $49(26 \%)$ began with other bilateral patterns. The primary focus was a sphenoid electrode with or without surrounding anterior to mid-temporal involvement, in all but six seizures in which the focus was at TS.

In this study an additional 49 seizures did become focal at a sphenoid after beginning with another pattern. However, when we examined the distribution of time required for the initial pattern to change to a second pattern, we found that $76 \%$ had changed within $10 \mathrm{sec}$ and another $16 \%$ changed by $20 \mathrm{sec}$. Thus, in most temporal lobe seizures the electrographic patterns had evolved in less than $15 \mathrm{sec}$ with a mean of $8.4 \pm 6 \mathrm{sec}$ (s.d.). and classifying the EEG as focal after delays of greater than 10 sec was not statistically justifiable. There were no seizures with a focal onset that appeared to be extra temporal.

Interictal EEG's from the temporal lobe patients showed that 17 patients of 32 had focal sharp waves or spikes on at least one EEG (53\%). Two of $18(11 \%)$ focal interictal EEGs showed spiking outside the temporal lobe.

\section{Frontal Lobe Epilepsy}

In the pure frontal group with 172 seizures only 21 or $12 \%$ had a focal ictal onset with another 14 becoming focal after a delay. No one electrode was favored over others with respect to this focality. 41 seizures began regionally (24\%), 5 began as lateralized patterns $(3 \%)$, and $61 \%$ began as bilateral slowing or as a generalized low voltage fast pattern. The ictal patterns evolved to another by $5 \mathrm{sec}$ in $31 \%$ and by $10 \mathrm{sec}$ in $81 \%$. The mean time of pattern evolution was $8.5 \pm 6 \mathrm{sec}$ (s.d.).

Forty-four percent of the patient's interictal EEG's had focal sharp waves or spikes on at least one EEG. One of these foci (11\%) appeared to be within the temporal lobe.

\section{Temporal-Frontal/Frontal-Temporal Epilepsy}

These groups were combined because of the similarities in the EEG patterns. There were 55 seizures in the temporal-frontal group (TF), 31 of which began focally $(57 \%)$, with 2 lateralized at onset $(4 \%)$, and $40 \%$ began as bilateral slowing or diffuse attenuation (low voltage fast patterns). In the fronto-temporal (FT) group 10 of $20(50 \%)$ began as a focal pattern with the other 10 beginning in a bilateral or diffuse fashion. Combining the two groups, a total of $54.5 \%$ began focally, $3 \%$ began as a lateralized pattern and $42.5 \%$ began in a diffuse or bilateral pattern at onset $(n=75)$. The mean time for one pattern to evolve to another was $6.5 \pm 3.1$ (s.d.) sec. in this group. $48.5 \%$ had changed from the initial to a second pattern by $5 \mathrm{sec}$ and $85 \%$ had done so by $10 \mathrm{sec}$. $25 \%$ had focal interictal spikes or sharp waves in the TF/FT group.

\section{Frontal-Parietal Group}

Five patients having 21 recorded seizures were in this group. 15 or $71 \%$ began as a focal pattern at C3-P3 or C3-Cz. The rest $(29 \%, \mathrm{n}=6)$ began as bilateral spike and wave or attenuated patterns. $20 \%$ of the interictal EEG's had focal sharp waves or spikes in this group.

\section{Differences in the Groups}

A summary of these results is given in Tables $2 a, 2 b$, and $3 a$ $\& 3 b$ and Figure 6 . There is a two-fold increase in seizures beginning focally in the temporal lobe epilepsy group vs the frontal lobe group. Can we include those seizures which begin as diffuse attenuation or bilateral slowing and later become focal in the focal group? Using an analysis of variances we previously showed that in temporal lobe epilepsy, outcome was related to ictal onset type, with patients who had either focal or regional onsets showing better outcomes following temporal lobectomy compared to those with bilateral, lateral or diffuse attenuation onsets. ${ }^{56}$ In addition, one of the patients with cingulate epilepsy had phase reversing sharp waves at a sphenoid electrode within seconds of the surface EEG seizure onset. Therefore we do not think it valid to include those patients whose seizures became focal after a diffuse plus bilateral onset amongst the focal group. Our past analysis supported the validity of combining regional and focal groups with respect to outcome. ${ }^{56}$ The percentages of seizures beginning either focally or regionally are identical (36.5\% and $36 \%$, respectively) for frontal and temporal lobe seizures. Similarly, frontal and temporal groups show the same percentage of diffuse or bilateral onsets. Of interest is the fact that the TF/FP groups and the frontalparietal groups have higher percentage of focal onsets than either frontal or temporal lobe seizures. 


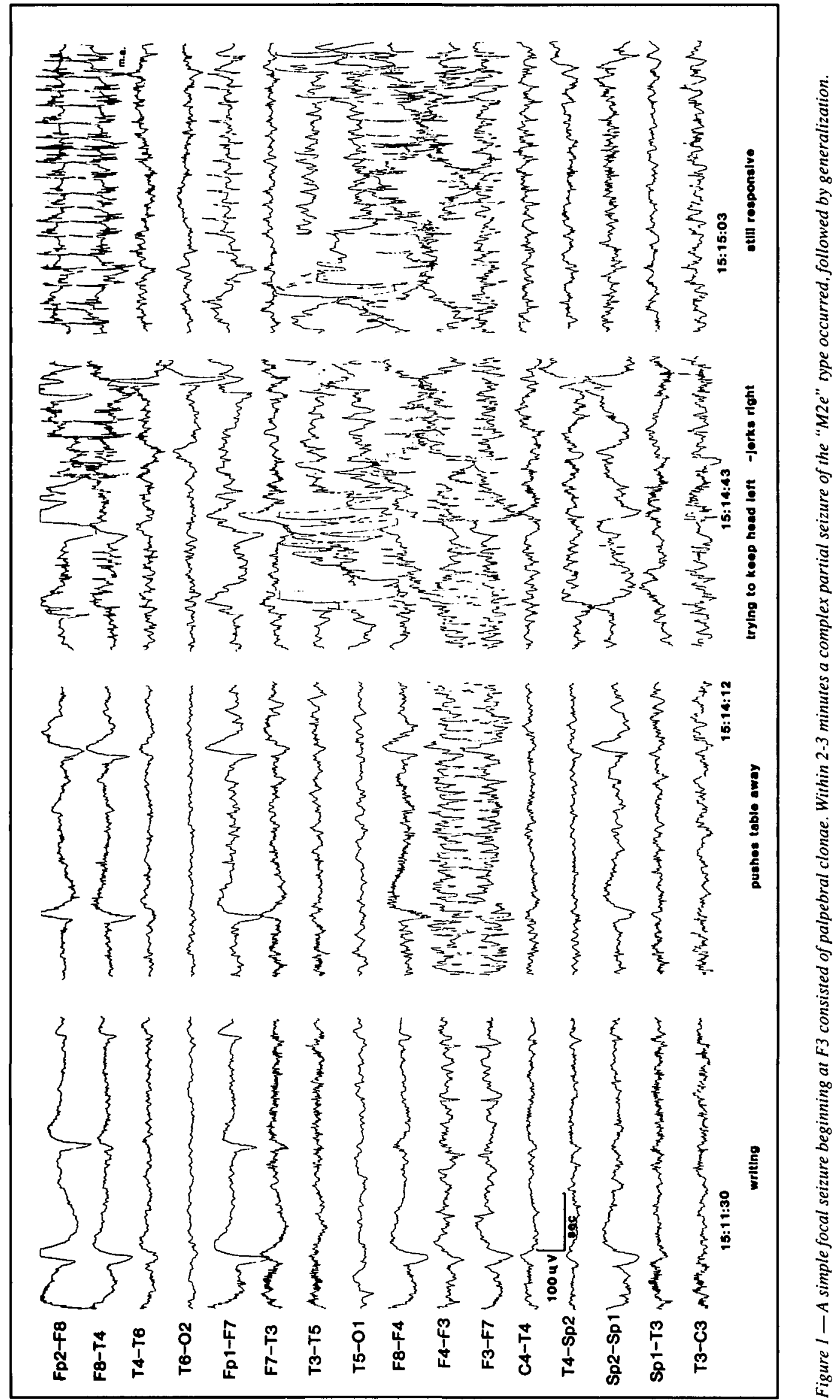




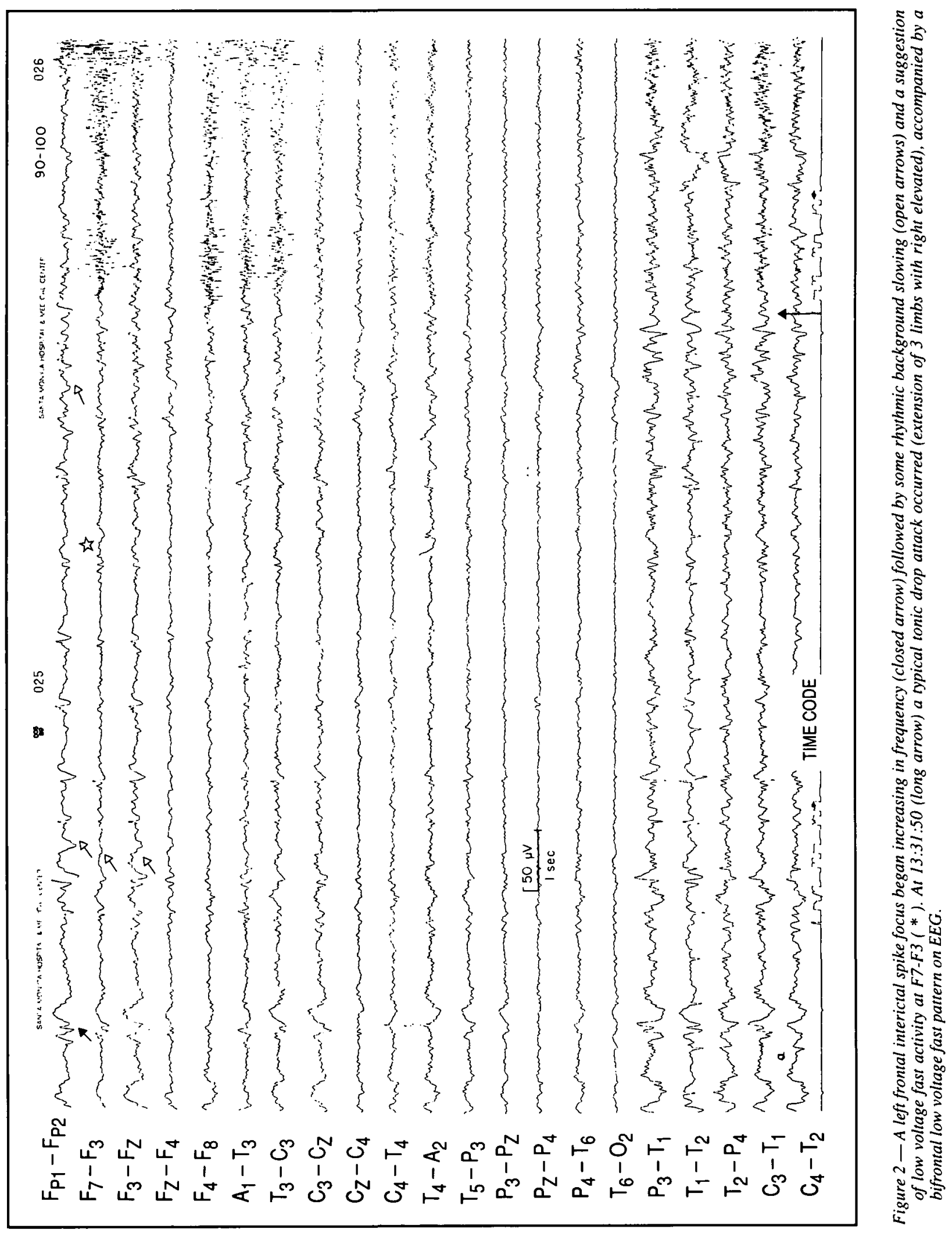




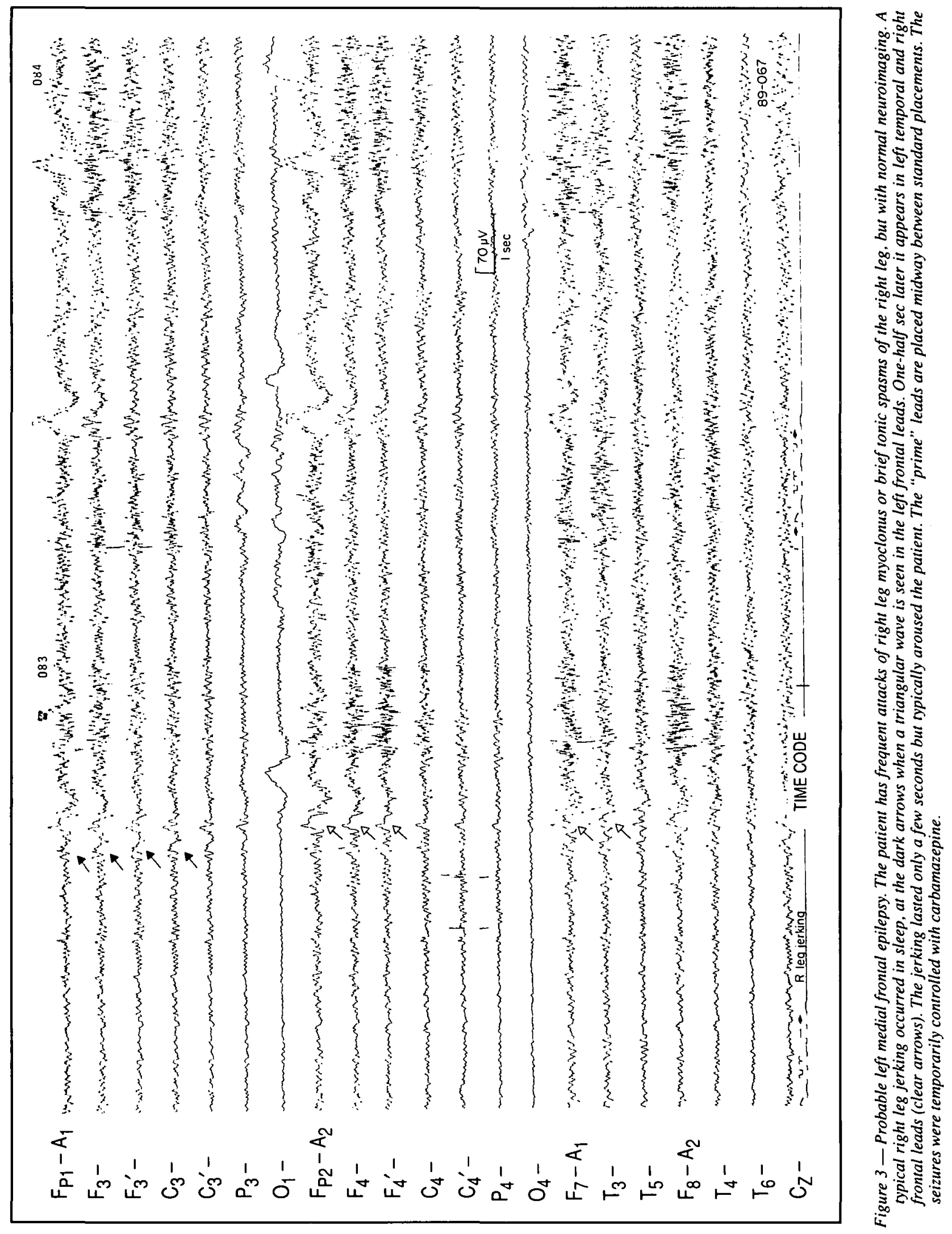




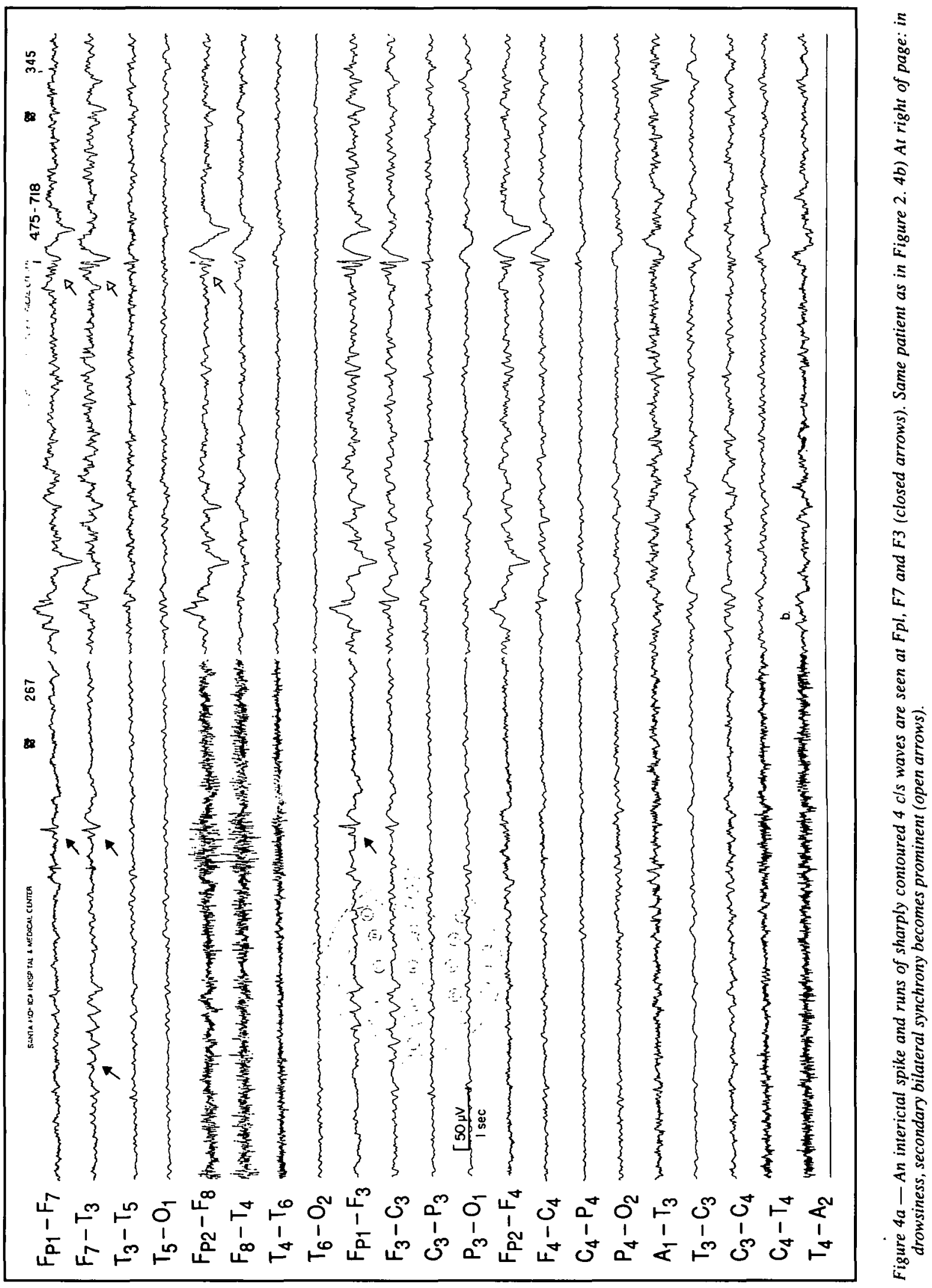




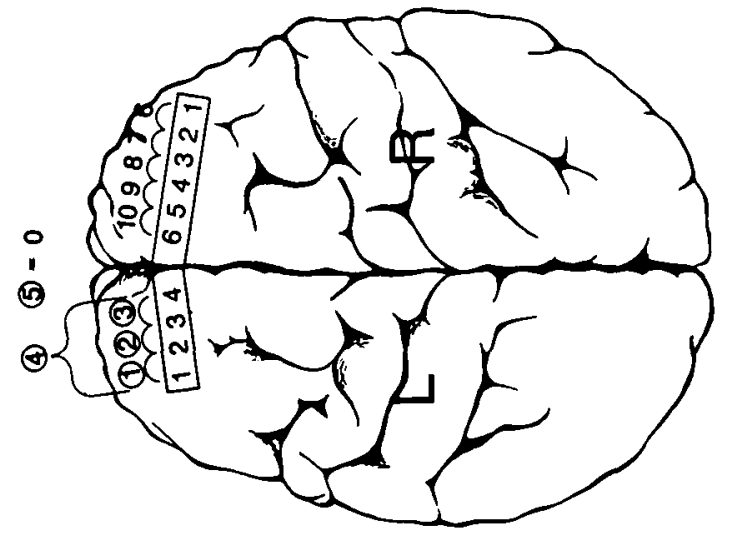

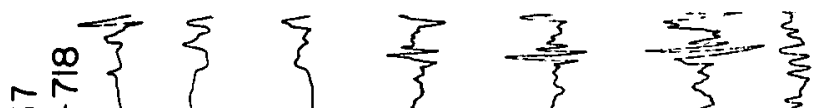

in

\&

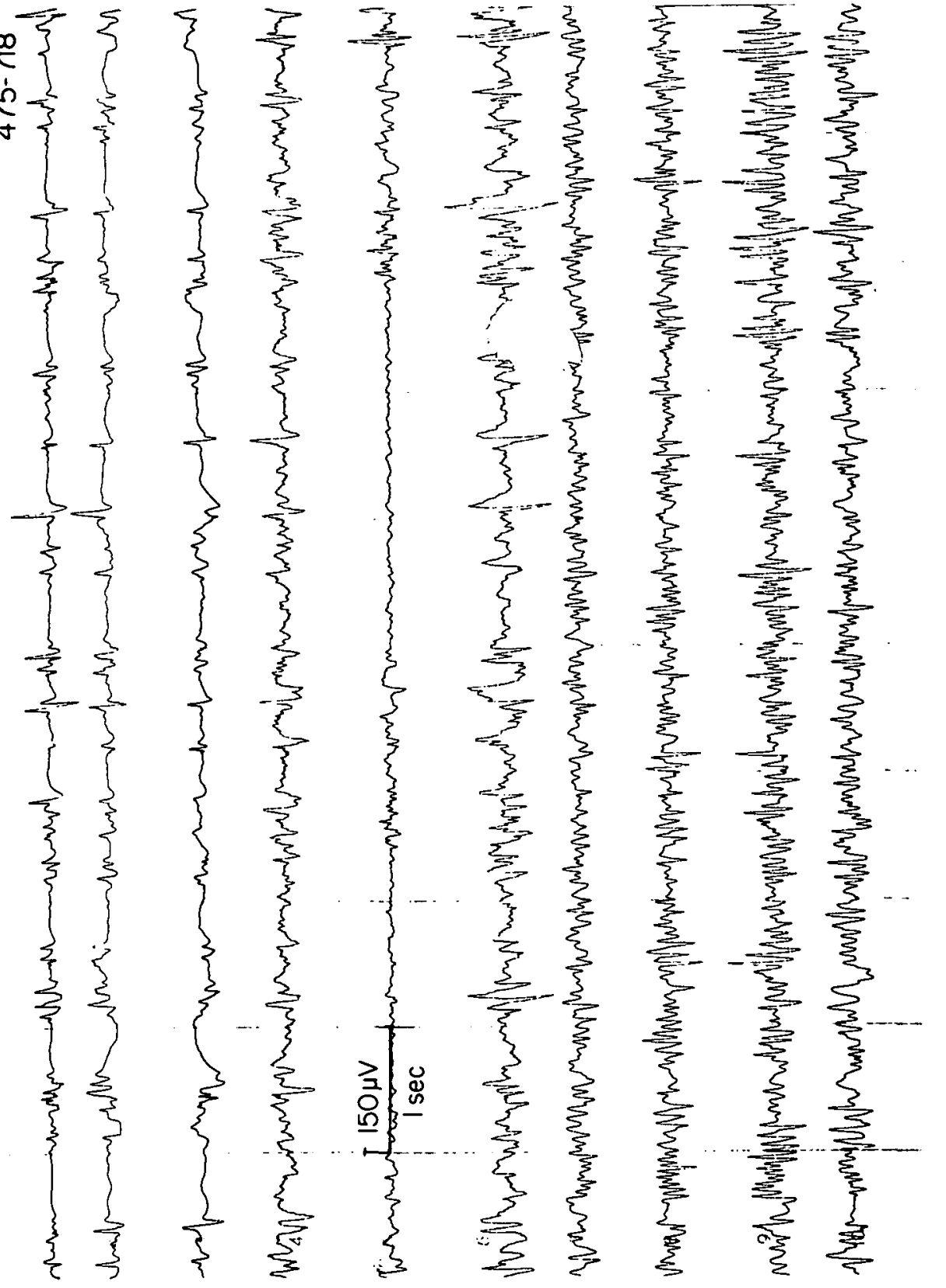

$\stackrel{2}{2}$

केष

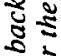

$\overline{8} \frac{2}{2}$

这亭

㱐

इั

\&

氙

בิ

$\approx \bar{y}$

iั

동

ริำ

호

․․․

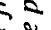

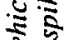

ป

$\frac{2}{2}$

ป

ธ옹

ฐ

8

ธิั

ปे

ร

¿

ำ

ปัฐ

赵赵

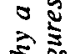

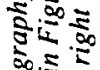

50.

施

过

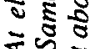

1 政

की

ํํㄴ돈

2 


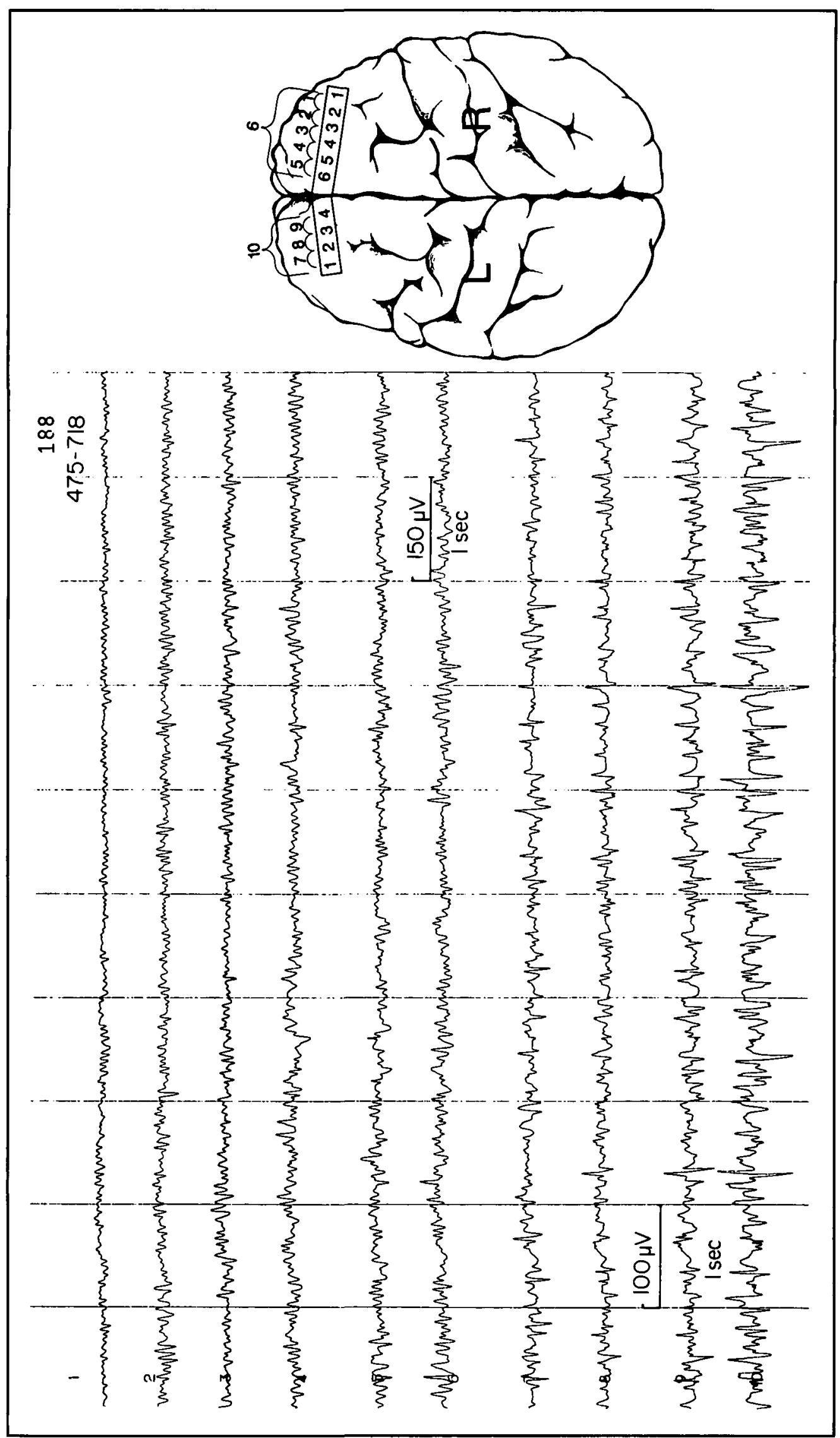

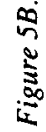


If we combine seizures whose patterns became focal after a regional, lateral, bilateral or diffuse onset with the focal onset seizures our percentages are nearly identical to those published by Quesney 14,15 (Tables 1a, 1b, 2b).

There appears to be a greater percentage of focal interictal EEG's with temporal than with frontal, temporal/frontal frontal/temporal, or frontal - parietal epilepsy when only one EEG was considered per patient. However, the ratio of accurate to inaccurate EEG's is the same for the frontal and temporal groups. Increasing the number of interictal EEG's per patient increased the incidence of patients with a focal EEG from $46.5 \%$ to $55 \%$ in the temporal group and from $33 \%$ to $53 \%$ in the frontal group.
Distribution of Onset Types and Times of Pattern Evolution

The interseizure variability of onset types within one patient has not been addressed to our knowledge. This interseizure variability may explain why, with extremely poor interobserver agreement on EEG interpretation in Spencer's study, 43 the EEG readers nevertheless had similar percentages of agreement between the proposed focus based on surface EEG as compared to the confirmed focus on depth recordings.

We recorded an average of 5.1 seizures per patient in the temporal lobe group with a mean of 1.8 onset types per subject. In the frontal lobe group there was a mean of 10 seizures per patient with 1.4 seizure onset types per patient. In the FT/TF

Table 2A: Electrographic Onsets in Focal Epilepsy

\begin{tabular}{|c|c|c|c|c|c|}
\hline & Focal & Regional & $\begin{array}{c}\text { Bilateral } \\
\text { or Diffuse }\end{array}$ & Lateral & $\begin{array}{c}\text { No. } \\
\text { Seizures }\end{array}$ \\
\hline Temporal & $26 \%$ & $10.5 \%$ & $62.5 \%$ & $1 \%$ & 190 \\
\hline Frontal & $12 \%$ & $24 \%$ & $61 \%$ & $3 \%$ & 173 \\
\hline $\mathrm{TF} / \mathrm{FT}{ }^{*}$ & $54.5 \%$ & $0 \%$ & $42.5 \%$ & $3 \%$ & 75 \\
\hline Fronto-parietal & $71 \%$ & $0 \%$ & $29 \%$ & $0 \%$ & 21 \\
\hline
\end{tabular}

*Temporal-frontal /Frontal-temporal

Table 2B: Electrographic Onsets in Focal Epilepsy

\begin{tabular}{lcccc}
\hline & $\begin{array}{c}\text { Initially or } \\
\text { Secondarily Focal }\end{array}$ & Regional & $\begin{array}{c}\text { Bilateral or } \\
\text { Diffuse }\end{array}$ & Lateral \\
\hline Temporal & $52 \%$ & $6.8 \%$ & $40 \%$ & $1.2 \%$ \\
Frontal & $20 \%$ & $24 \%$ & $53 \%$ & $3 \%$ \\
\hline
\end{tabular}

Table 3A: Interictal EEG Patterns in Focal Seizures

\begin{tabular}{lcccccc}
\hline \hline & Focal & Regional & Lateral & $\begin{array}{c}\text { (\% of EEG's) } \\
\text { Bilateral } \\
\text { or Diffuse }\end{array}$ & Normal & No. EEGs \\
\hline Temporal & $46.5 \%$ & $23.25 \%$ & $5 \%$ & $23.25 \%$ & $2 \%$ & 43 \\
Frontal & $33 \%$ & $18.5 \%$ & $13.5 \%$ & $33 \%$ & $3 \%$ & 27 \\
TF/FT * & $25 \%$ & $27.5 \%$ & $12.5 \%$ & $25 \%$ & $6 \%$ & 17 \\
$\begin{array}{l}\text { Fronto- } \\
\text { parietal }\end{array}$ & $20 \%$ & $20 \%$ & $40 \%$ & $20 \%$ & $0 \%$ & 5 \\
\hline
\end{tabular}

*Temporal-frontal / Frontal-temporal

\section{Table 3B}

\begin{tabular}{lccc}
\hline \hline & Focal Correct & Focal Incorrect & No. EEGs \\
\hline Temporal & 18 & 2 & 43 \\
Frontal & 8 & 1 & 27 \\
T-F/F-T & 3 & 1 & 17 \\
\hline
\end{tabular}

\footnotetext{
*Temporal-frontal / Frontal-temporal
} 
group there was an average of 7.5 seizures recorded with 1.5 onset types per patient. We previously reported that post-surgical outcomes in temporal lobe epilepsy are significantly better in those patients with more than $50 \%$ of focal or regional ictal onsets than those with $25 \%$ or less focal or regional onsets. ${ }^{56}$ Two few of our frontal lobe patients have had sufficient postoperative followup to determine if the same relationship holds in this group. Nevertheless, it is important to consider ictal variability when formulating one's hypothesis about the epileptogenic zone.

As mentioned, $76 \%$ of temporal lobe seizures show an evolution in the ictal pattern within $10 \mathrm{sec}$ of onset. Frontal lobe complex partial seizures have been described as very brief compared to temporal lobe seizures 11,15 although one of the earliest publications on this entity noted seizures lasting 2 to $5 \mathrm{~min} .{ }^{4}$ On the basis of depth recordings in temporal lobe seizures it has been suggested that rapid propagation of ictal discharges from the initial focus is associated with poor outcomes after temporal lobectomy. ${ }^{57}$ There was no differences in the mean \pm S.D. of the time of pattern evolution in the three groups which we studied. Comparing the distributions of the times required for an initial pattern to evolve in these three groups (temporal, frontal and the T/F-F/T group; Figure 6), there is still little difference in the groups. However, we note that the temporal group has a long tail due to seizures which never change their pattern (i.e. begin and remain focal or regional). This could explain why the seizures of temporal lobe origin are felt to be longer, although statistical analysis of that impression has not been performed.

\section{Discussion}

Although the surface EEG (interictal) has been used for over 30 years to define an epileptogenic focus, some authors have doubted its applicability. $2.33-37$ Dodrill, et al. ${ }^{58}$ found several surface interictal EEG variables were independently related to outcomes following surgical resection. Lieb, et al. ${ }^{57}$ also noted non-redundant information from interictal and ictal EEG records

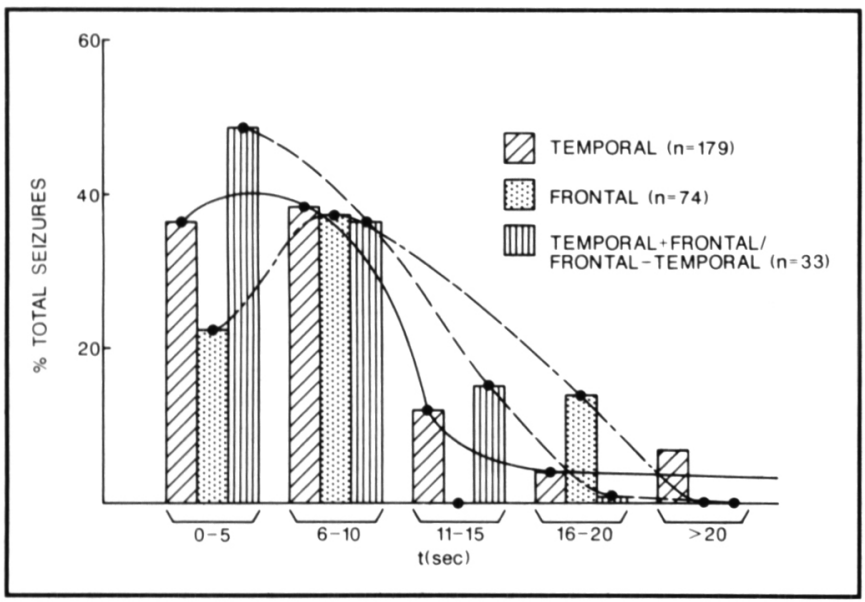

Figure 6-The time it took for a change in ictal pattern to occur after seizure onset is plotted against the total percentage of seizures as a histogram in bins of 5 seconds. While the combined TF/FT group appeared to change the fastest, few from any group changed after 10 seconds. The temporal lobe group has a few seizures which never change from the pattern at onset. with respect to outcomes. In preliminary studies we also reported a relationship between surface ictal EEG patterns and outcome $^{56,59}$ but did not look at interictal records.

The present study attempted to broaden our observations by comparing interictal and ictal records from frontal and temporal lobe epilepsy. We found $33 \%$ of frontal interictal EEG's to be focal, a figure intermediate with those in the literature and lower with those of our temporal epilepsy group. However, this figure was higher than the number of focal ictal onsets in the frontal seizure group. There was also a greater number of focal interictal than ictal EEG's in the temporal lobe seizure group. The lower number of focal ictal onsets is likely due to the fact that we did not combine diffuse low voltage fast or attenuated onsets which later became focal with the focal group as in studies from other centers. The ratio of focal EEGs on interictal to ictal records was approximately $3: 1$ for the frontal group and $2: 1$ for the temporal group. This difference in ratios is probably explained by the fact that in temporal lobe epilepsy the seizures begin or propagate rapidly to medial limbic structures, the hippocampus and amygdala, which are in good proximity to sphenoidal recording electrodes. ${ }^{60}$ Frontal lobe seizures can also propagate through medial limbic structures i.e. - from the superior dorsolateral frontal cortex to the cingulum via the supplementary motor area and from inferior premotor regions to posterior orbital frontal lobes.61 The latter structures are simply not as accessible to surface or special recording techniques such as the sphenoid. Thus, the ictal recordings may reveal a nonfocal EEG onset after it has moved from its site of origin, and this may be more true with frontal than with temporal lobe seizures. The focal interictal spike had a similar accuracy rate in both the frontal and temporal lobe epilepsy groups (Table 3B).

It is our impression that the study has not yet been done which definitively determines the true efficacy of surface EEG recordings. Such a study would require a specific hypothesis, i.e., extracranial EEG can accurately determine a focal epileptogenic zone. The focus as defined would have to be verified by results of intracranial recordings and surgery. The specificity of the intracranial recordings would have to be known exactly to determine the Type II error (beta statistic), in a relatively large population, and long follow-up periods would be required. This could be undertaken by one of several epilepsy surgery groups in the world and probably should be. Pending that, since many. operations have been successfully performed on the basis of surface EEG alone, and because in our temporal lobe series we found no significant differences in outcomes in those who did not have Phase II recordings, 56,59 we like others, feel comfortable continuing the use of this fundamental, noninvasive, diagnostic tool.

What of the differences in frontal and temporal lobe EEG ictal patterns? We noted that bilateral slowing or diffuse (i.e., general low voltage fast) patterns were equally common at onset in temporal and frontal lobe seizures. The proportion of regional plus focal onsets was also equal in the two groups. The main difference lay in the regional onset group which was twice as common in frontal as in temporal lobe seizures. This may be due to the "lobar" definition of regional in those studies which necessarily includes a greater area in the frontal lobe. Another contributing factor was that fewer of the diffuse onset ictal EEG's later became focal in frontal lobe epilepsy. Because a regional frontal onset implicates the entire frontal lobe, if 
surgery is considered intracranial recordings must be made. It is hoped that in the future improved brain imaging combined with EEG brain mapping or frontal activation paradigms paired with cognitive evoked potentials ${ }^{62,63}$ may provide improved noninvasive information.

There is a slightly greater variability in seizure onsets within a single patient in the temporal lobe group than in the frontal lobe group, which has not previously been evaluated. The ictal patterns appeared to evolve with similar time courses in the frontal, TF/FT, and temporal groups with $81 \%, 77 \%$, and $76 \%$ changing from an initial to secondary pattern within $10 \mathrm{sec}$, although one subdivision of the temporal lobe population never shows a pattern change. This similarity is curious since it has been suggested that frontal lobe seizures propagate faster than temporal lobe seizures. ${ }^{11,16,45,51}$ Speed of propagation cannot be determined from surface EEG recordings, therefore the interpretation of our data on ictal pattern development must be guarded, but bear further exploration. Practically, we believe that the term "onset" should only be applied to a pattern seen from the beginning of the electrographic seizure to no more than $10 \mathrm{sec}$ after onset, since most seizures change within this time period and since postsurgical outcomes in patients with initial focal records and initial attenuated records are not identical when stringent outcome criteria are used in temporal lobe epilepsy. ${ }^{56,59}$

\section{ACKNOWLEDGEMENTS}

The authors gratefully acknowledge the EEG technician skills of Nancy Kjelgaard and the manuscript preparation by Diane Guntrip. Supported in part by (Dept. of Veterans Affairs and the California Epilepsy Program).

\section{REFERENCES}

1. Rossi GF. Problems of analysis and interpretation of electrocerebral signals in human epilepsy. A Neurosurgeon's View. In: Brazier MAB, ed. Epilepsy: Its Phenomena in Man. New York: Academic Press 1973; 259-285.

2. Gloor P. Contributions of electroencephalography and electrocorticography to the neurosurgical treatment of the epilepsies. In: Purpura DP, Penry JD, Walter RD, eds. Neurosurgical Management of the Epilepsies. New York: Raven Press 1975; 59-105.

3. Quesney FA, Gloor P. Localization of epileptic foci. In: Gotman JJ, Ives JR, Gloor P, eds. Long-term Monitoring in Epilepsy. Electroencephalogr Clin Neurophysiol (Suppl 37). Elsevier Science Publ 1985; 165-200.

4. Fegersten L, Roger A. Frontal epileptogenic foci and their clinical correlations. Electroencephalogr Clin Neurophysiol 1961; 13: 905-913.

5. Rasmussen T. Surgery of frontal lobe epilepsy. In: Purpura DP, Penry JK, Walter RD, eds. Advances Neurology. New York: Raven Press 1975; 197-204.

6. Rasmussen T. Characteristics of a pure culture of frontal lobe epilepsy. Epilepsia 1983; 24: 482-493.

7. Ajmone-Marsan C, Abraham SK. A seizure atlas. Electroencephalograph Clin Neurophysiol 1957; 15 (Suppl 1): 215.

8. Ajmone-Marsan C, Abraham SK. Considerations on the use of chronically implanted electrodes in seizure disorders. Conf Neurol (Basel) 1966; 27: 95-110.

9. Ajmone-Marsan C, Goldhammer L. Clinical ictal patterns and electrographic data in cases of partial seizures of fronto-central-parietal origin. In: Brazier MAB, ed. Epilepsy: Its Phenomena in Man. New York: Academic Press 1973; 235-258.

10. Ludwig B, Ajmone-Marsan C, Van Buren J. Depth and direct cortical recording in seizures of extratemporal origin. Neurology 1975; 26 : 1025-1099.
11. Williamson PD, Spencer DD, Spencer SS, et al. Complex partial seizures of frontal lobe origin. Ann Neurol 1985; 18: 497-504.

12. Williamson PD, Spencer SS. Intensive monitoring for complex partial seizures. Epilepsia 1986; S46-63.

13. Williamson $P$, Wieser HG, Delgado-Escueta AV. Clinical characteristics of partial seizures. In: Engel J Jr, ed. Surgical Treatment of the Epilepsies. New York: Raven Press 1987; 101-123.

14. Quesney LF. Extracranial EEG Evaluation. In: Engel J Jr. Surgical Treatment of the Epilepsies. New York: Raven Press 1987; $167-$ 172.

15. Quesney LF, Krieger C, Leitner C, et al. Frontal Lobe Epilepsy: Clinical and EEG presentation. In: Porter RJ, et al., eds. Advances in Epileptology. XVth Epilepsy Intl Symposium. New York: Raven Press 1984; 503-508.

16. Bancaud J, Talairach J, Bonis A, et al. La stereo-electroencephalographie dans l'epilepsie. Paris: Masson 1965.

17. Bancaud J, Bonis A, Munari C, et al. Localizing value of the clinical manifestations of the partial seizures. Acta Neurochir (Wien) (Suppl) 1984; 33: 7-15.

18. Geier S, Bancaud J, Talairach J, et al. Automatisms during frontal lobe epileptic seizures. Brain 1976; 99: 447-458.

19. Geier S, Bancaud J, Talairach J, et al. The seizures of frontal lobe epilepsy: A study of clinical manifestations. Neurology 1977; 27: $951-958$

20. Morris HH, Dinner DS, Luders H, et al. Supplementary motor seizures: Clinical and electroencephalographic findings. Neurology 1988; 38(7): 1075-1082.

20a. Wyllie E, Lüder SH, Morris HH, Lesser RP, Dinner DS, Hahn J, Estes ML, Rothner AD, Erenberg G, Crus R, Friedman D. Clinical outcome after complete or partial resection for intractable epilepsy. Neurology 1987; 33(10): 1634-1641.

21. Delgado-Escueta AV, Swartz B, Maldonaldo H, et al. Complex partial seizures of frontal lobe origin. In: Wieser HG, Elger CE, eds. Presurgical Evaluation of the Epileptics. New York: Springer 1987.

22. Swartz BE, Delgado-Escueta AV. Extratemporal complex partial seizures: "The evidence for". In: Wieser HG, Speckmann EJ, Engel J Jr, eds. Current Problems in Epilepsy 1987; 137-174.

23. Walsh GO, Delgado-Escueta AV. Type II complex partial seizures: Poor results of anterior temporal lobectomy. Neurology (Cleveland) 1984; 34: 1-13.

24. Cahan L, Sutherling W, McCulough MA, et al. Review of the 20 year UCLA experience with surgery for epilepsy. Cleve Clin $Q$ 1984; 51: 313-318.

25. Swartz BE, Delgado-Escueta AV, Walsh GO, et al. Neuroimaging in focal epilepsy with pathological correlates. A retrospective review. Presented at Western EEG Society Meeting 1989; (Jan).

26. Delgado-Escueta AV. Seizures. In: Kelley WN, ed. Textbook of Internal Medicine. New York: J.D. Lippincott Co. 1990, in press.

27. Engel Jr J, Driver MV, Falconer MA. Electrophysiological correlates of pathology and surgical results in temporal lobe epilepsy. Brain 1975; 98: 129-156.

28. Rasmussen T. Surgery for epilepsy arising in regions other than the temporal and frontal lobes. In: Purpura DP, Penry JK, Walter RD, eds. Advances in Neurology. New York: Raven Press 1975; 207-226.

29. Walter RD. Principles of clinical investigation of surgical candidates. In: Purpura DP, Penry JD, Walter RD, eds. Neurosurgical Management of the Epilepsies. New York: Raven Press 1975; 49-58.

30. Gastaut H, Vigouroux M. Electroclinical correlations in 500 cases of psychomotor seizures. In: Baldwin M, Bailey P, ed. Temporal Lobe Epilepsy. Springfield: Thomas 1967; 118-128

31. Gloor P. The EEG in seizure disorders. A neurobiological view and some new technological applications. In: Symposia Specialists Inc. Chicago: Year Book of Medical Publishers 1980; 31-50.

32. Crandall PH. Developments in direct recordings from epileptogenic regions in the surgical treatment of partial epilepsies. In: Brazier MAB, ed. Epilepsy: Its Phenomena in Man. New York: Academic Press 1973; 287-310.

33. Crandall PH. Post-operative management and criteria for evaluation. In: Purpura DP, Penry KJ, Walter RD, ed. Advances in Neurology. New York: Raven Press 1975; 265-280. 
33a.Christodoulou G. Sphenoidal electrodes. Their significance in diagnosing temporal lobe epileptogenic foci. Acta Neurol Scand 1967; 43: 587-593.

34. Walter RD. Tactical considerations leading to surgical treatment of limbic epilepsy. In: Brazier MAB, ed. Epilepsy: Its Phenomena in Man. New York: Academic Press 1973; 99-119.

35. Wieser HG. Electroclinical features of the psychomotor seizure. 1983.

36. Spencer SS, Spencer DD, Williamson PD, et al. The localizing value of depth electroencephalography in 32 refractory epileptic patients. Ann Neurol 1982; 12: 248-253.

37. Spencer SS, Spencer DD, Williamson PD, et al. Sexual automatisms in partial complex seizures. Neurology 1983; 33: 527-533.

38. Ajmone-Marsan C. Depth electrography and electrocorticography in electrodiagnosis. In: Aminoff MJJ, ed. Clinical Neurology. New York: Churchill Livingston 1980; 167-196.

39. Ludwig B, Ajmone-Marsan C, Van Buren J. Depth and direct cortical recording in seizures of extratemporal origin. Neurology 1975; 26: 1025-1099.

40. Bancaud J. Role du cortex cerebral dans les epilepsies generalisees d'origine organique. Apport de investigations stereoencephalographiques (SEEG) a la discussion de la conception, centrencephalique. Presse Med 1971; 79: 669-673.

41. Bancaud J. Surgery of epilepsy based on stereotactic investigations - the plan of the SEEG investigation. Acta Neurochir (Wien) (Suppl) 1981; 30: 25-34.

42. Penfield W, Jasper H. Epilepsy and the Functional Anatomy of the Human Brain. 1954.

43. Spencer SS, Williamson PD, Bridgers SL, et al. Reliability and accuracy of localization by scalp ictal EEG. Neurology $1985 ; 35$ : $1567-1575$.

44. Engel Jr J, P.H., C. Falsely localizing ictal onsets with depth EEG telemetry during anticonvulsant withdrawal. Epilepsia 1983; 24 : 344-355.

45. Veilleux F, Saint-Hilaire JM, Giard N, et al. Clinical manifestations of seizures of the human medial frontal lobe. In: Chauvel P, Delgado-Escueta AV, Halgren E, et al., eds. Frontal Lobe Seizures and Epilepsies. New York: Raven Press 1990, in press.

46. Mazars G. Cingulate gyrus epileptogenic foci as an origin for generalized seizures. In: Gastaut $\mathrm{H}$, Jasper $\mathrm{H}$, Bancaud J, et al., ed. The Physiopathogenesis of the Epilepsies. Springfield: Charles C. Thomas 1969; 186-189.

47. Buser P, Bancaud J, Talairach J. Depth recordings in man in temporal lobe epilepsy. In: Brazier MAB, ed. Epilepsy: Its Phenomena in Man. New York: Academic Press 1973.
48. Tukel $\mathrm{K}$, Jasper $\mathrm{H}$. The EEG in parasagittal lesions. Electroencephalogr Clin Neurophysiol 1952; 4: $481-494$.

49. Ralston B. Cingulate epilepsy and secondary bilateral synchrony. Electroencephalogr Clin Neurophysiol 1961; 13: 591-598.

50. Neidermeyer E. The generalized multiple spike discharge. An electro-clinical study. Electroencephalogr Clin Neurophysiol 1966; 20: 133-138.

51. Mazars G. Criteria for identifying cingulate epilepsy. Epilepsia 1970; 11: $41-47$.

52. Gastaut H. The Epilepsies 1964; 149.

53. Risinger MW, Engel J Jr, Van Ness PC, et al. Ictal localization of temporal lobe seizures with $\mathrm{scal} / \mathrm{p} / \mathrm{sphenoidal}$ recordings. Neurology 1989; 39(10): 1288-1293.

54. King DW, Flanigan HF, Gallagher BB, et al. Temporal lobectomy for partial seizures: Evaluation, results and 1-year follow-up. Neurology 1986; 36(3): 334-339.

55. Maldonaldo HM, Delgado-Escueta AV, Swartz BE, Walsh GO, Halgren E, Rand RW. Distinguishing frontal from temporal lobe complex partial seizures. Epilepsia 1988; 29 (5): 706.

56. Swartz BE, Delgado-Escueta AV, Walsh GO. Ictal onsets on surface EEG in temporal lobe epilepsy. Epilepsia 1989; 30(5): 695-696.

57. Lieb JP, Engel JJ, Gevins A, Crandall P. Surface and deep EEG correlates of surgical outcome in temporal lobe epilepsy. Epilepsia $1981 ; 22$ : 515-538.

58. Dodrill CB, Wilkins RJ, Ojemann GA, et al. Multidisciplinary predictions of seizure relief from cortical resective surgery. Ann Neurol 1986; 20: 2-12.

59. Swartz BE, Delgado-Escueta AV. Predictors of post-surgical outcome in temporal lobe epilepsy. Presented at the Cleveland Clinic International Symposium on Epilepsy Surgery 1990 (July).

60. King DW, So EL, Marcus R, et al. Techniques and applications of sphenoidal recording. J Clin Neurophysiol 1986; 3(1): 51-65.

61. Nauta WJH. Neural associations of the frontal cortex. Acta Neurobiol Exp (Warz) 1972; 32: 125-140.

62. Hamer R, Sussmman NM, Jackel RA. EEG topography of epileptogenic zones in the frontal lobe. Epilepsia 1988; 29(2): 211.

63. Squires NK, Halgren E, Wilson CL, et al. Human endogenous limbic potentials: Cross modality and depth/surface comparisons in epileptic subjects. In: Gaitland AWK, Ritter W, eds. Amsterdam: N Holland 1983; 217-232. 